\title{
Peroxisome Proliferator-Activated Receptor $\gamma$ as a Therapeutic Target in Human Breast Cancer
}

\author{
Julie M. Hall* and Matthew L. Robinson
}

Department of Pharmaceutical Sciences, Campbell University, College of Pharmacy \& Health Sciences, Buies Creek, NC, USA

*Corresponding author: Julie M. Hall, Campbell University, College of Pharmacy \& Health Sciences, Box 1090, Buies Creek, NC 27506, USA, Tel: 9108931698; Fax: (910)893-1697; E-mail: halljm@campbell.edu

Rec date: May 04, 2015, Acc date: May 22, 2015, Pub date: May 29, 2015

Copyright: (c 2015 Hall JM, et al. This is an open-access article distributed under the terms of the Creative Commons Attribution License, which permits unrestricted use, distribution, and reproduction in any medium, provided the original author and source are credited.

\begin{abstract}
Objective: Peroxisome proliferator-activated receptor $\mathrm{y}$ (PPARY) is aberrantly expressed in most breast tumors, suggesting the potential of agents that target this receptor in treatment and chemoprevention of breast cancer. However, whether PPARy leads to the promotion or reduction of tumor formation has remained controversial and is further complicated by the ability of its available thiazolidinedione (TZD) ligands to activate another PPAR subtype, PPARס.
\end{abstract}

Method: To examine the role of each receptor in breast cancer biology, we performed a systematic evaluation of PPARY and PPARס agonists on the growth of human estrogen receptor (ER)-positive and -negative breast cancer cells.

Results: In this manner we found that TZD-activated PPARY was highly effective in suppressing the proliferation of estrogen-dependent cancer cells. Activated PPARס, however, displayed growth-enhancing effects independent of estradiol and regardless of the ER status of the cells. Strikingly, in ER-negative cancer cells expressing a favorable PPARס/y ratio, TZDs promoted growth in a PPAR $\gamma$-independent manner by direct activation of PPARס. A screen for ligands with increased receptor selectivity compared to TZDs revealed that GW7845 functioned as a full agonist of PPARy, yet this agent lacked the ability to activate PPARס and elicit its associated mitogenic effects.

Conclusion: These studies indicate that selective PPAR y modulators (SPPARyMs) that lack agonist activity on PPARס may be clinically useful in future cancer treatment and chemoprevention.

Keywords: PPAR $\gamma$; Thiazolidinedione (TZD); Breast cancer; Estrogen; ER; Subtype-selective; Proliferation

\section{Introduction}

Breast cancer is currently the most prevalent malignancy among women in industrialized countries, and one in eight women living in the United States will develop the disease at some point in her lifetime. It is estimated that over 230,000 women will be newly diagnosed with breast cancer in the United States this year, accounting for 30\% of cancers found in women [1]. Despite the increase in diagnostic technologies, incidence rates of distant-stage disease have remained stable over the past several decades [2]. A series of mechanistically distinct therapeutics are currently in clinical use, including those targeting estrogen and growth factor signaling pathways [3-5] Unfortunately, difficulties in mode of delivery, adverse cardiovascular effects, associated bone loss and development of resistance over time have provided limitations for sustained use of the many of these agents [5-9]. To date there still exists an unmet need for novel breast cancer therapeutics with improved tolerance, specificity and safety. Thus, further molecular characterization of the disease should aid in guiding both the most appropriate use of existing therapies and subsequent identification of new drug targets $[3,10]$.

The PPARs $(\alpha, \delta, \gamma)$, are nuclear hormone receptors that regulate lipid metabolism and homeostasis by regulating cell growth, differentiation and survival [11]. In addition to normal physiology, each receptor is associated with pathways linked to carcinogenesis, and thus, emerging evidence indicates a role for PPARs in the etiology of cancer [12]. While the link between each subtype and carcinogenesis is unclear, there is notable aberrant expression of PPAR $\gamma$ and its coactivator PGC-1 $\alpha$ in both ER-positive and ER-negative human breast tumors, where low levels of these factors are associated with poor clinical outcomes [13].

Given these observations, it is not surprising that PPAR $\gamma$ has recently become a prospective target for prevention and treatment of breast cancers [14]. While the available PPAR $\gamma$ ligands were developed for their ability to normalize blood glucose levels in patients with type II diabetes, analogous to the selective estrogen receptor modulator (SERM) concept, it has been proposed that selective PPAR $\gamma$ modulators (SPPAR $\gamma \mathrm{Ms}$ ) may be clinically useful in future cancer chemoprevention [14]. However, the development of such agents has been hindered by the uncertainty as to whether PPAR $\gamma$ activation or inhibition is the desired effect. In vitro and in vivo studies have revealed that PPAR $\gamma$ physiological ligands (prostaglandins; lipids) and pharmacological ligands (thiazolidinediones (TZDs)) effectively inhibit growth and induce apoptosis in human breast cancer cells and tumors, yet not in normal breast epithelial cells [15-19]. Yet other studies using several cancer cell lines, animal models, and a variety of PPAR $\gamma$ agonists have shown discordant results, perhaps due to differences in tumor type, grade, species and pharmacological dose 
[20,21]. Thus, despite early concurrence as to the protective effects of the receptor, whether PPAR $\gamma$ leads to the promotion or reduction of tumor formation currently remains somewhat controversial.

The apparent confounding effects of available PPAR $\gamma$ ligands on PPAR $\delta$ have the potential to further complicate the development of SPPAR $\gamma \mathrm{Ms}$ as breast cancer therapeutics. A biological impact of 'receptor crossover' was demonstrated in human macrophages. Specifically, TZDs, which possess established anti-inflammatory actions through activation of PPARy, were shown to display unanticipated pro-inflammatory activities in a PPAR $\gamma$-independent manner through direct activation of PPAR $\delta$ [22]. Whether similar, nonspecific activities of PPAR $\gamma$ ligands could occur in breast cancers is not clear, nor is it know whether this phenomenon might explain the one clinical trial to date evaluating TZDs in metastatic breast cancer patients, which failed to demonstrate efficacy of troglitazone as a breast cancer therapeutic [23]. Regardless, the potential for 'receptor crossover' suggests that the ratio of PPAR $\gamma$ to PPAR $\delta$ expression could alter both tumor biology and drug pharmacology. This is particular alarming given that the two receptors are co-expressed in most breast cancers and PPAR $\delta$ has been implicated in promoting development and expansion of tumors from several tissue origins [24-27]. Clearly, an understanding of the role of each receptor in regulating growth of cancer cells should allow for future development of safer, yet effective PPAR modulators with potential therapeutic use for cancer. We undertook these studies therefore with the intent to determine the impact of PPAR $\gamma$ and PPAR $\delta$ expression in breast cancer and to evaluate the contribution of each receptor to breast cancer biology.

\section{Materials and Methods}

\section{Biochemicals}

PCR reagents were obtained from BIO-RAD (Hercules, CA). 17 $\beta$ estradiol and GW9662 were purchased from Sigma (St. Louis, MO). Rosiglitazone, pioglitazone, troglitazone, ciglitazone, and carbaprostacyclin were purchased from Cayman Chemical (Ann Arbor, MI). GSK660 was a gift from Drs. Andrew Billin and Barry Shearer (GlaxoSmithKline). The FluoReporter Blue Fluorometric dsDNA Quantitation Kit, transfection reagents, and PCR oligos were purchased from Life Technologies (Grand Island, NY).

\section{Mammalian cell culture and ligand treatments}

All cell lines were obtained from American Type Culture Collection (Manassas, VA). MCF-7, ZR-75 and T47D (human ER-positive breast cancer) cells and MDA MB-231 (human ER-negative breast cancer) cells were maintained in DMEM F12 medium supplemented with $10 \%$ fetal calf serum (FCS), $2 \mathrm{mM}$ glutamine, $0.1 \mathrm{mM}$ nonessential amino acids, and $1 \mathrm{mM}$ sodium pyruvate (Life Technologies). HeLa (human cervical cancer) cells were maintained in MEM supplemented with $10 \%$ FCS. Cell were grown in a $37^{\circ} \mathrm{C}$ incubator with $5 \% \mathrm{CO}_{2}$. For RNA analysis, cells were plated at $60 \%$ confluency in 6-well culture dishes in $2 \mathrm{ml}$ phenol red-free DMEM F12 containing 8\% charcoal-stripped FCS (HyClone Laboratories, Inc., Logan, UT) for $24 \mathrm{~h}$ prior to treatment. Media was then replaced and supplemented with ethanol (vehicle), 17 $\beta$-estradiol, rosiglitazone, carbaprostacyclin, pioglitazone, troglitazone, ciglitazone, GSK660 or GW7845. Note figure legends for details on concentrations of agents used in specific experiments. For some studies GW9662 (PPAR $\gamma$ antagonist) or GSK660 (PPAR $\delta$ antagonist) was co-administered with vehicle or treatments. For cell proliferation assays, cells were induced with vehicle, $17 \beta$-estradiol or other agents.

\section{RNA isolation and quantitative PCR}

RNA was isolated from cultured BG-1 cells using the RNeasy kit (Qiagen, Valencia, CA). One $\mu \mathrm{g}$ of RNA was reverse transcribed using the BioRad iScript cDNA synthesis kit. The ABI PRISM 7900HT Real Time PCR System was used to amplify and quantitate levels of target gene cDNA. Quantitative PCR (qPCR) reactions were performed using $0.1 \mu \mathrm{l}$ of cDNA, $10 \mu \mathrm{M}$ gene-specific primers, and $2 \mathrm{x}$ SYBR Green Mastermix (Applied Biosystems). Data are the mean +/-STDEV of three biological replicates performed in triplicate. All experiments were repeated a minimum of three times. The following primers were used: CXCL12,

\begin{tabular}{|c|c|c|}
\hline 5'-GTGGTCGTGCTGGTCCTC-3' & (for) & and \\
\hline ATGCTTGACGTTGGCTCTG-3' & Cyclin & D1, \\
\hline GCTGCGAAGTGGAAACCATC-3’ & (for) & and \\
\hline ССТССТTCTGCACACATTTGAA-3' & (rev), & p21, \\
\hline TGTCCGTCAGAACCCATGC-3'(for) & and & \\
\hline AAAGTCGAAGTTCCATCGCTC-3' & $(\mathrm{rev})$, & $\mathrm{pS} 2$, \\
\hline CGGGGAGTGAGAAACCCTC-3’ & (for) & and \\
\hline CACTGGAGTCGAAACAGCATC-3’ & (rev), & PR \\
\hline ACCCGCCCTATCTCAACTACC-3' & (for) & and \\
\hline AGGACACCATAATGACAGCCT-3’ & $(\mathrm{rev})$, & ID3, \\
\hline GAGAGGCACTCAGCTTAGCC-3’ & (for) & and \\
\hline 'TCCTTTTGTCGTTGGAGATGAC-3' & (rev), & 36B4 \\
\hline GACATGTTGCTGGCCAATAA-3' & (for) & and \\
\hline
\end{tabular}

\section{Cell proliferation assays}

For standard assays, cells were seeded and adhered in 96-well plates at $2.5 \times 10^{4}$ cells/well. Cells were incubated in the absence or presence of ligands for $96 \mathrm{~h}$ in phenol red-free DMEM F12 containing 8\% charcoal-stripped FCS $(100 \mu \mathrm{l} /$ well $)$. After $96 \mathrm{~h}$, cell proliferation was measured using the FluoReporter Blue Fluorometric dsDNA Quantitation Kit according to the manufacturers' protocols (Life Technologies). All values were corrected for fluorescence values read from blank controls containing media with no cells. Sextuplicate biological replicates were used for each treatment condition in each experiment, and data are the mean +/-STDEV of the 6 replicates. All experiments were repeated a minimum of three independent times.

\section{Mammalian cell transfections}

HeLa cells were used for transactivation and mammalian-twohybrid assays. For transient transfections, cells were plated in 24-well plates $24 \mathrm{~h}$ before transfection. Lipofectin-mediated transfection has been described in detail previously [22]. Briefly, prior to transfection, the media was replaced with phenol-free MEM containing $8 \%$ charcoal-stripped serum (Hyclone), $0.1 \mathrm{mM}$ non-essential amino acids and $1 \mathrm{mM}$ sodium pyruvate (Life Technologies). A DNA-Lipofectin mixture containing a total of $3 \mu \mathrm{g}$ of plasmid for each triplicate sample was added to the cells. For transactivation assays, each triplicate contained $2 \mu \mathrm{g}$ DR1-Luc, $0.1 \mu \mathrm{g}$ pCMV- $\beta g a l, 0.1 \mu \mathrm{g} \operatorname{pcDNA3-PPAR}(\gamma$ or $\delta$ ), and $0.8 \mu \mathrm{g}$ PBSII filler vector. For mammalian two-hybrid assays, each triplicate contained $1.5 \mu \mathrm{g} 5 \mathrm{x}$-Gal4-TATA-Luc, $0.1 \mu \mathrm{g}$ pCMV- $\beta$ gal, $0.7 \mu$ g pVP16-PPAR $(\gamma$ or $\delta$ ) and $0.7 \mu$ g pM-ASC- 2 . Receptor ligands were added to cells $4 \mathrm{~h}$ following transfection. Cells were assayed $40 \mathrm{~h}$ following transfection. Luminescence was measured 
on a Fusion luminometer (Perkin Elmer) and $\beta$-galactosidase activity on a Multiskan MS plate reader (Thermo Labsystems). Results are expressed as normalized luciferase activity (normalized with $\beta$-Gal for transfection efficiency) per triplicate sample of cells in a representative experiment; error bars indicate the S.E.M. of triplicate determinations. Each experiment was repeated at least three independent times with very similar results.

\section{Results}

It has been well established that gene expression patterns have the ability to define clinically relevant risk factors in disease prognosis [28-30]. The aberrant over-representation of PPARs in breast cancers, together with their suspect roles in tumor biology, prompted us to investigate the relationship between PPAR $\gamma$ and $\delta$ expression, receptor activity, and associated impact on cancer biology. Thus, in the following series of studies, human breast cancer cell lines, containing endogenous expression of both PPAR subtypes, were used as a simplified system to study the respective roles of the two receptors.

\section{PPAR $\gamma$ agonists attenuate estradiol-dependent growth of human breast cancer cells}

The majority of human breast tumors over-express ER $\alpha$ and grow in response to estrogens, making this signaling system a primary target for therapeutic intervention [31]. Given that ER+ breast cancer cells also express PPAR $\gamma$, the impact of TZDs on the growth of ER-positive breast cancer cells was examined. However, no effects of pharmacological doses of rosiglitazone or other TZDs were observed when administered in the absence of estrogen stimulation despite the detection of biologically active PPAR $\gamma$ in all cell lines examined (Figure 1A and not shown).

Given that the growth of ER+ cancer cells is estrogen-dependent, agents that when co-administered display anti-estrogenic (antiproliferative) activity are of keen therapeutic interest. Thus, the effect of rosiglitazone on estrogen-stimulated growth of three ERa/PPAR $\gamma$ positive breast cancer cell lines was next examined (Figure 1A). Each of the MCF-7, ZR-75, and T47D cell lines displayed a mitogenic response to estradiol that was partially (T47D-50\% inhibition) to completely (MCF-7) attenuated with co-administration of rosiglitazone. Interestingly, the degree of inhibition positively correlated with the expression levels of PPAR $\gamma$ in each of the three cell lines. Co-administration of the PPAR $\gamma$-selective antagonist GW9662 rendered cells resistant to the antiproliferative effects of rosiglitazone, demonstrating the observed growth inhibitory effects were receptordependent (Figure 1B). Annexin V staining confirmed that the observations made in these experiments reflected changes in proliferation rather than in apoptosis. Together these data indicate that agonist-activated PPAR $\gamma$ can effectively attenuate the growth of estradiol-dependent breast cancer cells.

\section{PPAR $\gamma$ agonists oppose estradiol in modulating expression of key regulators of growth}

In most target tissues PPAR $\gamma$ expression is associated with cell differentiation and ERa with proliferation [32,33], and these activities are reflected in the gene expression profiles of each receptor [34,35]. Given that both receptors are expressed in breast cancer cells $[13,31]$ and were found to display opposing effects on cell growth (Figure 1), it seemed possible that the signaling pathways of the activated receptors might converge at the genomic level.

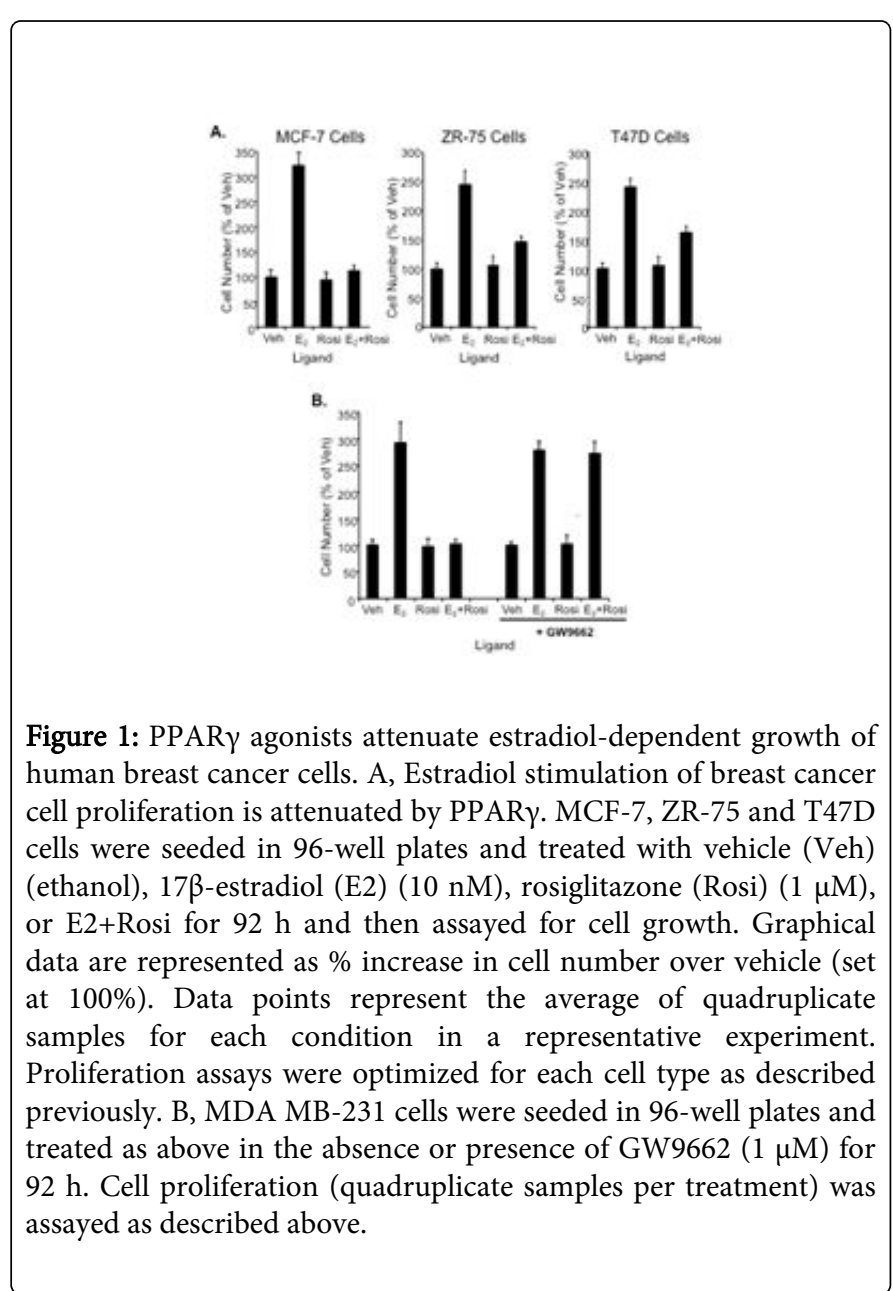

To address this possibility, the gene expression patterns of MCF-7 cells administered estradiol, rosiglitazone or both agents were evaluated by microarray analysis. Quantitative real-time PCR (qPCR) was used to verify the effects of each receptor on the expression of several genes that exhibited differential expression profiles in the microarrays. Figure 2 shows the qPCR results from MCF-7 cells administered estrogen in the presence or absence of PPAR $\gamma$ agonist. Strikingly, rosiglitazone completely suppressed estrogen-stimulated induction of two known regulators of breast cancer growth, C-X-C motif chemokine 12 (CXCL12) and Cyclin D1. Furthermore, rosiglitazone displayed inverse agonist activity, decreasing CXCL12 and Cyclin D1 mRNA expression below that observed in vehicle treated cells. This effect was not specific for rosiglitazone as all other PPAR $\gamma$ ligands tested, both TZDs and others, displayed similar activity on CXCL12 expression in this assay. Rosiglitazone and estradiol also displayed opposing effects on the cell cycle inhibitor p21, although in this instance the estradiol-mediated response was dominant when the two agents were co-administered.

Although ER and PPAR signaling may converge in some aspects of cell growth, the receptors likely have independent gene targets associated with other cellular activities. This in fact was reflected in our gene validation analysis, as the expression of the estrogen responsive progesterone receptor (PR), $\mathrm{pS} 2$ and ID3 mRNAs remained unchanged with the addition of PPAR $\gamma$ agonists (Figure 2B). These data indicate that PPAR $\gamma$ agonists can oppose estradiol in modulating 
Citation: Hall JM, Robinson ML (2015) Peroxisome Proliferator-Activated Receptor $\mathrm{y}$ as a Therapeutic Target in Human Breast Cancer. J

Page 4 of 9

expression of key regulators of growth in human breast cancer cells, an activity consistent with the suppressive effects of these agents on estrogen-dependent proliferation.

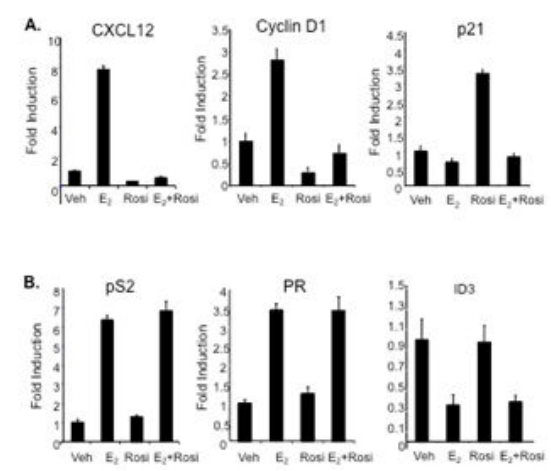

Figure 2: PPARy agonists oppose estradiol in modulating expression of key regulators of growth in breast cancer cells. A, Real-time PCR analysis of endogenous CXCL12, Cyclin D1 and p21 expression or B, endogenous pS2, PR and ID3 expression in MCF-7 cells. MCF-7 cells were grown for $48 \mathrm{~h}$ in phenol-red free DMEM + $10 \%$ stripped FCS and then treated with vehicle (Veh) (ethanol), $17 \beta$-estradiol (E2) $(10 \mathrm{nM})$, rosiglitazone (Rosi) $(1 \mu \mathrm{M})$, or E2+Rosi. After $24 \mathrm{~h}$, cells were harvested for total RNA, which was used for real-time PCR. Graphical data are represented as fold induction over vehicle (set at 1). Data points represent the average of triplicate amplification reactions for each condition in a representative experiment.

\section{PPAR $\gamma$ promotes growth of human breast cancer cells}

The effect of activated PPAR $\delta$ on breast cancer cell growth was next examined. Notably, the PPAR $\delta$ agonist carbaprostacyclin (Carb) enhanced proliferation of MCF-7 and T47D cells in a manner comparable to that of estrogen (Figure 3A). Co-administration of Carb did not enhance the effects of estradiol, however, additive effects of the two agents were seen when assayed at lower, sub-efficacy doses (not shown). The specific PPAR $\delta$ antagonist GSK660 [36] completely attenuated Carb-induced growth, demonstrating that the growthstimulatory effects were receptor-mediated (Figure $3 \mathrm{~A}$ ). Interestingly, the inverse agonist effects of GSK660 suggest that PPAR $\delta$ might have constitutive growth-promoting effects. This possibility is supported by previous findings that the receptor displays significant basal activity in the absence of an added ligand [22,37]. As a control, HeLa cells, which lack detectable activity of both ER and PPARs, exhibited no effects of any of the agents tested; this further ensured that the observed growth inhibitory activity of GSK660 were not due to a general effect on cell survival (Figure 3B). Thus, PPAR $\delta$ stimulates the growth of human breast cancer cells, and this activity appears to be manifest in both a ligand-independent and -dependent manner.

\section{Rosiglitazone can stimulate breast cancer cell growth by activating PPARס.}

The results thus far have suggested contrasting roles of the two PPAR subtypes in breast cancer, whereas PPAR $\gamma$ may be protective, yet PPAR $\delta$ activity might be unfavorable.

In this context, previous observations that saturating doses TZDs can activate PPAR $\delta$ are concerning given that as agonists of PPAR $\gamma$ one would expect TZDs to be protective in cancer [22]. Since whether PPAR $\gamma$-independent activities of these ligands could occur in breast cancers is not clear, to test this possibility, the impact of different pharmacological doses of TZDs on growth of breast cancer cells was next examined. While Rosi administered at a subsaturating quantity $(100 \mathrm{nM})$ had no significant impact in the assay, at a micromolar dose Rosi displayed growth-stimulatory effects in a manner comparable to that of the PPAR $\delta$ agonist Carb (Figure 3C). Co-administration of the PPAR $\delta$ agonist GSK660 completely attenuated these effects, suggesting that the mitogenic activity of Rosi was in fact occurring by activation of PPAR $\delta$. This was further supported by the inability of the PPAR $\gamma$ specific antagonist GW9662 to block Rosi-stimulated proliferation. Thus, at saturating concentrations Rosi can function as a PPAR $\delta$ agonist and elicit the growth-promoting activity of the receptor in human breast cancer cells.

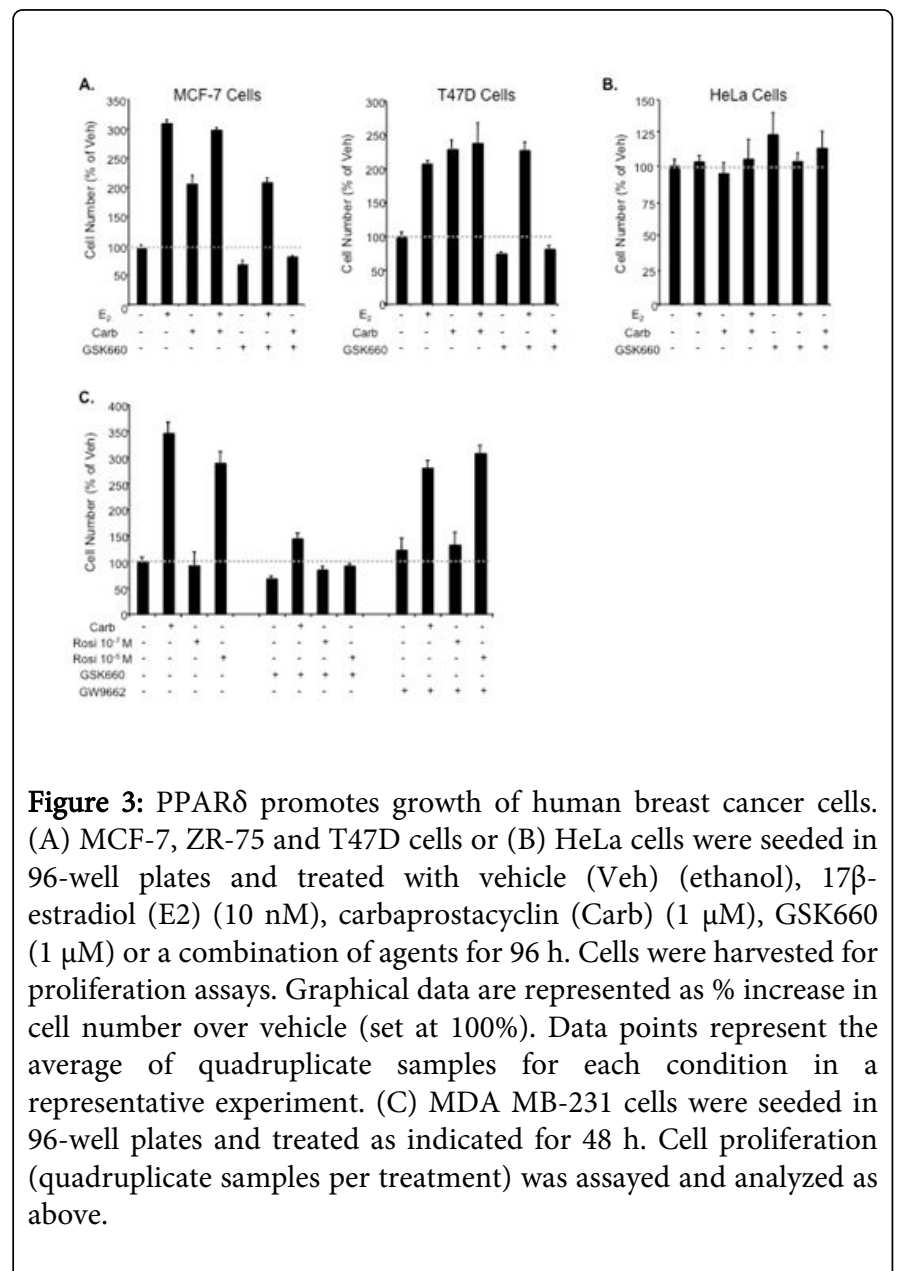




\section{GW7845 is a PPAR $\delta$-Sparing PPAR $\gamma$ agonist}

One of the key goals of this study was to assess whether drugs that target PPAR $\gamma$ might have promise as future breast cancer therapeutics. While it appears that activation of PPAR $\gamma$ would be the desired effect of such agents, unfortunately, available receptor agonists have undesirable feature of cross-reactivity with PPAR $\delta$.

We therefore undertook a screen for ligands with increased receptor selectivity compared to TZDs. The ability of a series of 30 known PPAR $\gamma$ agonists and SSPAR $\gamma$ Ms to activate PPAR $\gamma$, PPAR $\alpha$ and PPAR $\delta$ was evaluated in mammalian cells.

Specifically, PPAR negative HeLa cells were used for these assays, enabling us to measure the transcriptional responses of each receptor in isolation. HeLa cells were transfected with expression plasmids for either PPAR $\gamma$ PPARa or PPAR $\delta$ in combination with a DR1-luc reporter. All results shown reflect receptor activity at maximal efficacy for a particular agent (Figure 4A). None of the test compounds were capable of activating PPARa (not shown); this was not entirely surprising given the indications that this receptor is somewhat more discriminatory in ligand preferences [38-40]. However, in evaluation of PPAR $\gamma$ and PPAR $\delta$ in the assay, one compound, GW7845, functioned as a subtype-selective, full agonist of PPAR $\gamma$ (Figure 4A). Specifically, while all 4 TZDs as shown previously were effective activators of PPAR $\delta$, GW7845 displayed modest inverse agonist activity on the receptor. Others, however, have also demonstrated that GW7845 does indeed bind PPAR $\delta$ and modulate its structure [41,42].

Classical nuclear receptor agonists function by binding to the receptor and inducing an activating conformational change that facilitates recruitment of transcriptional coactivators. The observation that GW7845 was a PPAR subtype-selective agonist suggested that the agent might differ in its ability to promote cofactor recruitment to PPAR $\gamma$ and PPAR $\delta$. Mammalian two-hybrid assays were next used to compare the ability of GW7845 and TZDs to facilitate an interaction between the AF-2 domain of $\mathrm{PPAR} \gamma / \delta$ and the nuclear receptor interacting domain (NR-box) of the coactivator Activating Signal Cointegrator 2 (ASC-2) (Figure 4B). HeLa cells were transfected with pM-ASC-2 (NR-Box), containing the yeast Gal4 transcription factor DNA-binding domain fused to the ASC-2 NR-Box, and VP16-PPAR $\gamma$ or VP16-PPAR $\delta$ which are chimeras of the strong Herpes Simplex virus VP16 activation domain fused to $\mathrm{N}$-terminus of each PPAR. Transcriptional readout, a measurement of protein-protein interactions in the assay, was obtained by cotransfection of a luciferase reporter vector containing five tandem Gal4 binding sites $(5 \mathrm{xGal} 4$ Luc). Notably, a substantial amount of ASC-2 interaction with both PPAR $\gamma$ and $\delta$ was observed in the absence of ligand (Figure 4C). This likely reflects the fact that in the absence of an added activating ligand PPARs reside in an active conformation, as shown previously [22,37]. Despite the high basal level of ASC-2 binding, GW7845 enhanced the interaction with PPAR $\gamma$ in a manner comparable to that of all four TZDs (Figure 4C). Likewise, Carb and TZDs enhanced cofactor binding to PPAR $\delta$; these interactions were completely antagonized by GSK660, indicating that all compounds were binding in the known ligand-binding pocket of the receptor. GW7845, conversely, demonstrated inverse agonist activity in the ability to partially disrupt the basal interaction of PPAR $\delta$ with ASC-2. Thus, GW785 is mechanistically and functionally distinct from other known PPAR modulators, as the agonist activity of this agent is PPAR $\gamma$-selective.

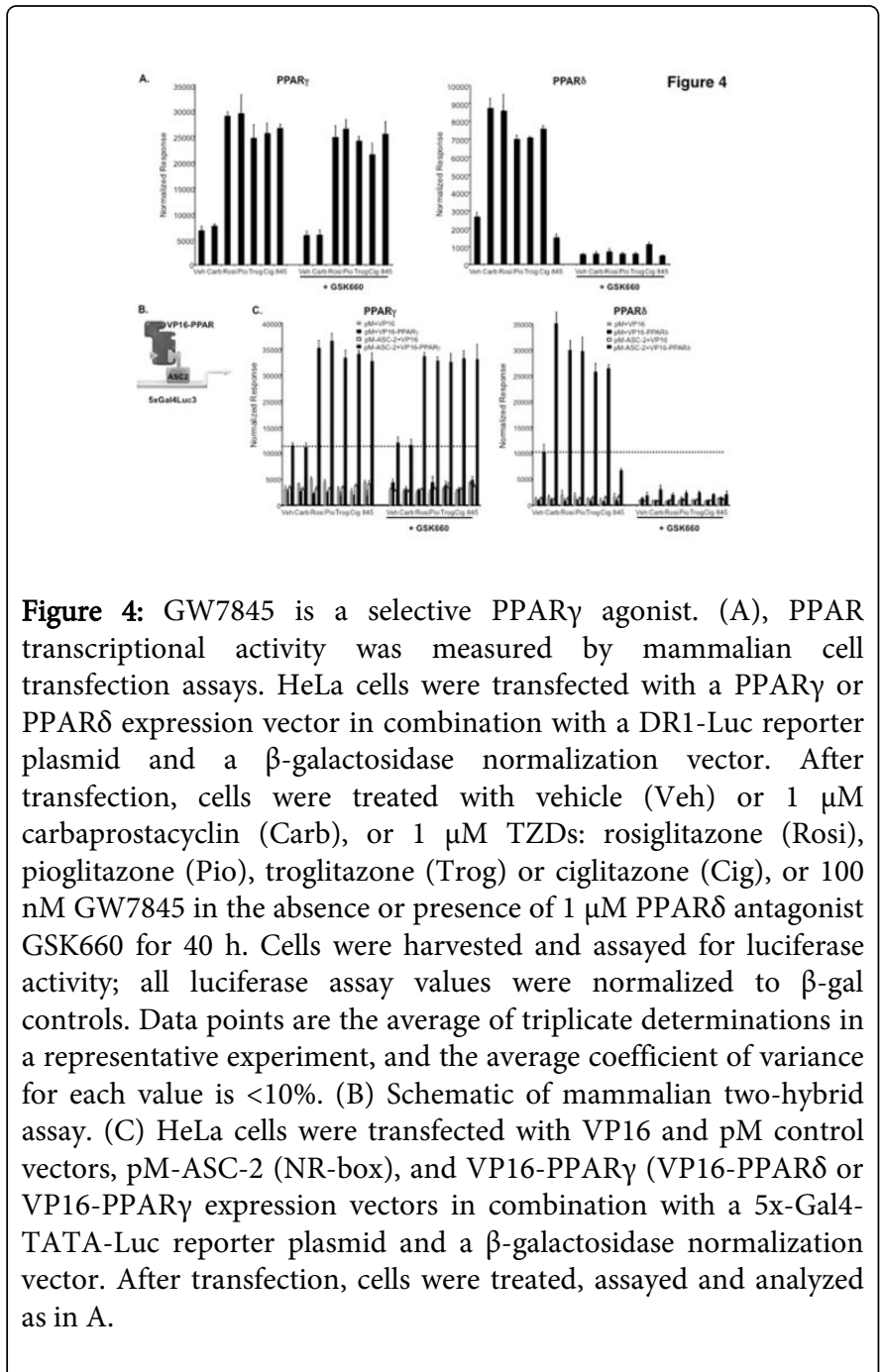

\section{GW7845 manifests the anti-proliferative effects of PPAR $\gamma$ without inducing the proliferative effects of activated PPARס.}

Given that TZD-activated PPAR $\gamma$ is effective at suppressing growth in estrogen-dependent breast cancer cells (Figure 1), it would be predicted that GW7845 as a full receptor agonist should behave similarly. Thus, the effect of GW7845 on estrogen-stimulated growth of two ER $\alpha / P P A R \gamma$-positive breast cancer cell lines was next examined (Figure 5A). Both the MCF-7 and ZR-75 cells displayed a mitogenic response to estradiol that was completely attenuated with coadministration of GW7845. Furthermore, GW7845 displayed a modest anti-proliferative activity when administered alone, further suggesting that this compound might possess inverse agonist activity on PPAR $\delta$ as seen beforehand (Figures $4 \mathrm{~A}, 4 \mathrm{~B}$ and $5 \mathrm{~A}$ ).

Despite the apparent protective effects of TZDs, their ability to activate the proliferative effects of PPAR $\delta$ at high doses is concerning (Figure 3B). If as our studies have suggested GW7845 is indeed superior to the TZDs in receptor selectivity, at saturating doses this agent should not display agonist activity through PPAR $\delta$. In investigating this possibility, as seen before (Figure $3 \mathrm{~B}$ ), Rosi when present at a micromolar concentration enhanced proliferation in a 
PPAR $\delta$-dependent in a manner that was comparable to that of full agonist Carb (Figure 5B). Given the potency of GW7845 is 1-2 log values superior to that of TZDs [18], 10-fold lower doses than those used for Rosi were administered. Regardless, GW7845 failed to evoke a proliferative response in the assay (Figure 5B). Thus the PPAR subtype-selective activities of GW7845 are reflected in both its receptor pharmacology (Figure 4) and biology in breast cancer cells (Figure 5).

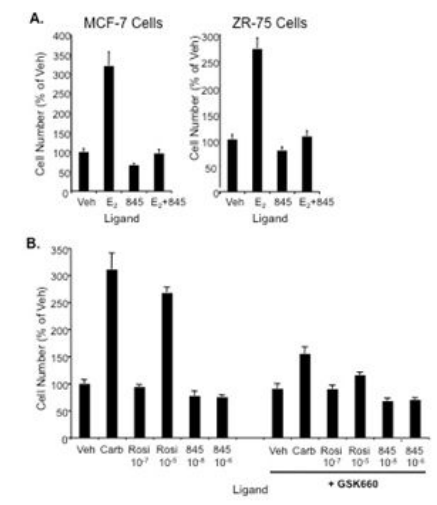

Figure 5: GW7845 manifests the anti-proliferative effects of PPAR $\gamma$ without inducing the proliferative effects of PPAR $\gamma$. (A) MCF-7 and ZR-75 cells were seeded in 96-well plates and treated with vehicle (Veh), 17 $\beta$-estradiol (E2) (10 nM), GW7845 (100 nM), or E2+GW7845 for $96 \mathrm{~h}$. Cells were harvested for proliferation assays. Graphical data are represented as \% increase in cell number over vehicle (set at $100 \%$ ). Data points represent the average of quadruplicate samples for each condition in a representative experiment. (B) MDA MB-231 cells were seeded in 96-well plates and treated with vehicle (Veh), carbaprostacyclin (Carb) $(1 \mu \mathrm{M})$, rosiglitazone (Rosi) (100 $\mathrm{nM}$ or $10 \mu \mathrm{M})$, GW7845 (10 nM or $1 \mu \mathrm{M})$ in the absence or presence of GSK660 $(1 \mu \mathrm{M})$ for $96 \mathrm{~h}$. Cell proliferation (quadruplicate samples per treatment) was assayed and analyzed as above.

\section{Discussion}

\section{$\operatorname{PPAR} \gamma$-selective agonists as promising therapeutics for breast cancer}

Together, the observations made in this study suggest a potential therapeutic value of subtype-selective PPAR $\gamma$ agonists in treatment of breast cancer. This was evidenced by the efficacy with which GW7845 suppressed the growth of estrogen-dependent cancer cells. Clearly this agent has an advantage over available PPAR $\gamma$ ligands such as TZDs, which we show can manifest agonist activity through PPAR $\delta$ and elicit mitogenic actions of the receptor in breast cancer cells. In fact it appears that PPAR $\gamma$-selectivity need only be in regards to the agonist activity of a compound, as GW7845, while acting as a PPAR $\gamma$-selective agonist could also display antagonist activity through PPAR $\delta$. This was supported by observations that GW7845 promoted binding of transcriptional coactivators to PPAR $\gamma$ and corepressors to PPAR $\delta$ [42]. Importantly, both the agonist and antagonist activities of GW7845 contribute to its anti-proliferative role in breast cancer cells.
Thus, PPAR 'pan-compounds,' with dual PPAR $\gamma$ agonist/PPAR $\delta$ antagonist activities, could be highly effective as breast cancer therapeutics as they would capitalize on the protective actions of PPAR $\gamma$ whilst blocking both the constitutive and ligand-activated proliferative effects of PPAR $\delta$. As a potent and highly selective PPAR $\delta$ antagonist has been characterized [36], it may be possible to use structural information from this molecule to create a GW7845-like chemical with enhanced antagonist activity on PPAR $\delta$. Additionally, as the available PPAR $\gamma$ ligands were developed for their ability to normalize blood glucose levels in patients with type II diabetes, it is likely that anti-proliferative effects can be optimized further.

An important implication of our study was the potential to develop PPAR $\gamma$ modulators in treatment of ER-positive breast cancer. Given the high percentage (approximately 70\%) of breast tumors that express both ERa and PPAR $\gamma$ the effectiveness with which activated PPAR $\gamma$ could interfere with ER signaling was striking. It was of further note that with the complexity of the gene expression profiles induced by ER in breast cancer cells [34] PPAR $\gamma$ influenced expression of only a small handful of estrogen-regulated genes. Thus, the activated receptor could completely attenuate estrogen-dependent cell proliferation without interfering with other ER functions. This high degree of process-specificity is something lacking in many of the currently available breast cancer therapeutics that target ER signaling yet often relay adverse side-effects. For example, the aromatase inhibitors (AIs), anastrozole and letrozole (Arimidex, Femara), which block estrogen biosynthesis in all tissues, are known to cause bone loss, hot flashes, arthralgia and myalgia, and significantly increase the risk of cardiovascular disease and osteoporosis [43-45]. While fewer sideeffects are generally associated with the selective estrogen receptor modulator (SERM) tamoxifen (Nolvadex), this agent does markedly increase the incidence of endometrial cancer, endometriosis, thrombosis and stroke; furthermore, drug-resistance is a currently a serious problem associated with both tamoxifen and the AIs [44-46]. Thus, while tremendous efforts have been made by the pharmaceutical industry to create better AIs and SERMs, PPAR $\gamma$ agonists, in their ability to function as process-targeted ER-modulators, may in fact fulfill both the need for effective and safer therapeutics for ER-positive breast cancers.

Unlike the available ER-targeted therapeutics for breast cancer, PPAR $\gamma$ modulators may also have utility in prevention and treatment of ER-negative tumors. Notably, GW7845 was shown to decrease the incidence, number, and weight of tumors in a nitrosomethylureaexperimental rat model of ER-negative mammary carcinogenesis [18]. In the current study, a modest yet significant effect of GW7845 on growth of ER-negative cancer cells was observed. However, unlike the studies with ER+ cells, which included stimulation with estrogen, the ER-negative cancer cells studies excluded the use of growth activators and rather examined effects of PPAR ligands only on basal proliferation. This is may be an important oversight, as there is emerging evidence that PPAR $\gamma$ may interfere with several signal transduction pathways associated with growth activators that are overrepresented in ER-negative tumors. For example, HER-2/neu and epidermal growth factor receptor (EGFR) are over-expressed in $20-30 \%$ breast carcinomas, the majority of which are ER-negative. PPAR $y$ agonists were shown to both cause dose-dependent decreases in levels of HER-2/neu and EGFR in human breast epithelial cells and to display inhibitory cross-talk with these receptors [47-49]. Increased Wnt signaling is also implicated in the development of mammary carcinomas, and notably, PPAR $\gamma$ can function to suppress tumorigenesis and/or Wnt signaling by targeting phosphorylated $B$ - 
catenin to the proteasome [50]. As a follow up to the current study, therefore, we intend to test the effects of PPAR $\gamma$ modulators on the EGFR, HER2 and Wnt pathways of cell growth with anticipation that in a scenario of "activated-proliferation" receptor agonists will demonstrate much more dramatic inhibitory effects.

\section{PPARs as predictive biomarkers in breast cancer}

Previous studies noted that low levels of PPAR $\gamma$ are correlated with decreased survival in breast cancer patients whereas PPAR $\gamma$ expression is correlated with increased survival rate. Specifically, ligand-activated PPAR $\gamma$ upregulates the tumor suppressor 'phosphatase and tensin homolog' (PTEN), an event thought to help mediate the antiproliferative effect of the receptor in breast and other cancer types $[51,52]$. Furthermore, it seems that the mere presence of the receptor is protective even in the absence of pharmacological intervention. Whether the ligand constitutive activity of the receptor is adequate to confer protection is not known, although it is also anticipated that sufficient quantities of endogenous ligands for receptor activation might be present in breast tissues.

Recently, clinical data has also revealed that PPAR $\delta$ expression in breast tumors is associated with poor prognosis (our unpublished data). Likewise, there exists strong evidence linking the receptor to related pathologies in other tissues. Analysis of PPAR $\delta$ in matched normal and tumor samples revealed a remarkable upregulation of the receptor in colon carcinomas [53]. Others suggested a supporting role of the receptor in events controlling initiation and progression of cancers in the colon. Specifically, marked increases in PPAR $\delta$ expression are evident from normal intestinal mucosa to precancerous polyps to colorectal cancer cells, to cancer cells with malignant morphology [54]. In contrast, PPAR $\gamma$ was demonstrated to be protective in colon carcinoma cells, as the increases in receptor expression induced by the tumor suppressor Zac, were associated with anti-proliferative effects [55]. Together, these observations indicate that association of PPAR and PPAR $\delta$ with differing outcomes in cancer may be more broadly applicable, and likewise, the two receptors may be useful predictive biomarkers for other types of cancers. Our observations also suggest factors that increased expression of PPAR $\gamma$ or PPAR $\delta$ has the potential to influence breast cancer biology and patient survival rates.

The concept that PPAR $\gamma$ may function as a protective agent in some cancers may explain some of the correlations that have been made between diet and breast cancer. Interestingly, trans fatty acid intake at levels of human consumption can decrease PPAR $\gamma$ levels in women by $40 \%$ in reproductive tissues. In fact, decreases in receptor levels in the ovary due to high intake of trans fatty acids were recently associated with a increased incidence of infertility. Apparently the changes in $\operatorname{PPAR} \gamma$ levels were sufficient to interfere with fertility, as when the women began a treatment regimen of PPAR $\gamma$ agonists there was a consistent and significant increase in ovulatory function [56]. In addition to potential effects of dietary fats, $\alpha$ and $\gamma$ tocopherol (Vitamin E) can upregulate the expression of the receptor in colon cancer cells, where PPAR $\gamma$ is considered an important molecular target for chemoprevention [57]. There are reports that levels of HDL cholesterol positively correlate with $\mathrm{PPAR} \gamma$ expression; while a direct association is not clear, it is known that cardiovascular health is often associated with decrease risk of breast and other cancers [58]. Regardless, it will be interesting to determine whether dietary-related changes in PPAR expression can significantly impact the incidence, progression and reoccurrence of cancers.
In summary, in this study we report that at therapeutically relevant levels TZDs can activate PPAR $\delta$ and elicit its mitogenic effects, whereas in the same contexts PPAR $\gamma$-specific agonists can effectively inhibit the growth of human breast cancer cells and tumors. These discoveries provide an explanation for several puzzling observations made previously, such as the ability of TZDs to manifest PPAR $\gamma$ independent effects and the controversy surrounding whether PPAR $\gamma$ enhances or reduces cancer risk. Given the observed growthpromoting activity of the human PPAR $\delta$, we suggest that PPAR $\gamma$ modulators with increased specificity show promise as safer, more effective therapeutics for breast tumors and perhaps other cancers.

\section{Acknowledgements}

The authors would like to thank Drs. Andrew Billin and Barry Shearer (GlaxoSmithKline) for their generous gift of the PPAR $\delta$ antagonist GSK660. An American Association of College of Pharmacy (AACP) New Investigator Award and an Internal Research Grant from Campbell University (to J.M.H.) supported this work.

\section{References}

1. American Cancer Society (2015) What are the Key Statistics for Breast Cancer. http://www.cancer.org/cancer/breastcancer/detailedguide/ breast-cancer-key-statistics. Accessed May 3, 2015.

2. Komen SG (2015) Breast cancer statistics.

3. Doyle DM, Miller KD (2008) Development of new targeted therapies for breast cancer. Cancer Treat Res 141: 119-134.

4. Lin NU, Winer EP (2008) Optimizing Endocrine Therapy for Estrogen Receptor-Positive Breast Cancer: Treating the Right Patients for the Right Length of Time. J Clin Oncol 26: 1919-1921.

5. Lin NU, Winer EP (2008) Advances in adjuvant endocrine therapy for postmenopausal women. J Clin Oncol 26: 798-805.

6. Hadji P, Bundred N (2007) Reducing the risk of cancer treatmentassociated bone loss in patients with breast cancer. Semin Oncol 34: S4-10.

7. Iorns E, Turner NC, Elliott R, Syed N, Garrone O, et al. (2008) Identification of CDK10 as an important determinant of resistance to endocrine therapy for breast cancer. Cancer Cell 13: 91-104.

8. Perez EA (2007) Safety profiles of tamoxifen and the aromatase inhibitors in adjuvant therapy of hormone-responsive early breast cancer. Ann Oncol 18 Suppl 8: 26-35.

9. Urruticoechea A (2007) The oestrogen-dependent biology of breast cancer. Sensitivity and resistance to aromatase inhibitors revisited: a molecular perspective. Clin Transl Oncol 9: 752-759.

10. Muscat GE, Eriksson NA, Byth K, Loi S, Graham D, et al. (2013) Research resource: nuclear receptors as transcriptome: discriminant and prognostic value in breast cancer. Mol Endocrinol 27: 350-365.

11. Moore KJ, Rosen ED, Fitzgerald ML, Randow F, Andersson LP, et al. (2001) The role of PPAR-gamma in macrophage differentiation and cholesterol uptake. Nat Med 7: 41-47.

12. Michalik L, Desvergne B, Wahli W (2004) Peroxisome-proliferatoractivated receptors and cancers: complex stories. Nat Rev Cancer 4: 61-70.

13. Jiang WG, Douglas-Jones A, Mansel RE (2003) Expression of peroxisome-proliferator activated receptor-gamma (PPARgamma) and the PPARgamma co-activator, PGC-1, in human breast cancer correlates with clinical outcomes. Int J Cancer 106: 752-757.

14. Sporn MB, Suh N, Mangelsdorf DJ (2001) Prospects for prevention and treatment of cancer with selective PPARgamma modulators (SPARMs). Trends Mol Med 7: 395-400.

15. Zaytseva YY, Wallis NK, Southard RC, Kilgore MW (2011) The PPARgamma antagonist T0070907 suppresses breast cancer cell 
proliferation and motility via both PPARgamma-dependent and independent mechanisms. Anticancer Res 31: 813-23.

16. Lea MA, Sura M, Desbordes C (2004) Inhibition of cell proliferation by potential peroxisome proliferator-activated receptor (PPAR) gamma agonists and antagonists. Anticancer Res 24: 2765-2771.

17. Nunez NP, Liu H, Meadows GG (2005) PPAR-gamma ligands and amino acid deprivation promote apoptosis of melanoma, prostate, and breast cancer cells. Cancer Lett 236: 133-141.

18. Suh N, Wang Y, Williams CR, Risingsong R, Gilmer T, et al. (1999) A new ligand for the peroxisome proliferator-activated receptor-gamma (PPAR-gamma), GW7845, inhibits rat mammary carcinogenesis. Cancer Res 59: 5671-5673.

19. Wang PS, Chou FS, Porchia L, Saji M, Pinzone JJ (2008) Troglitazone inhibits cell migration, adhesion, and spreading by modulating cytoskeletal rearrangement in human breast cancer cells. Mol Carcinog 47: 905-915.

20. Mueller E, Sarraf P, Tontonoz P, Evans RM, Martin KJ, et al. (1998) Terminal differentiation of human breast cancer through PPAR gamma. Mol Cell 1: 465-470.

21. Saez E, Rosenfeld J, Livolsi A, Olson P, Lombardo E, et al. (2004) PPAR gamma signaling exacerbates mammary gland tumor development. Genes Dev 18: 528-540.

22. Hall JM, McDonnell DP (2007) The molecular mechanisms underlying the proinflammatory actions of thiazolidinediones in human macrophages. Mol Endocrinol 21: 1756-1768.

23. Burstein HJ, Demetri GD, Mueller E, Sarraf P, Spiegelman BM, Winer EP (2003) Use of the peroxisome proliferator-activated receptor (PPAR) gamma ligand troglitazone as treatment for refractory breast cancer: a phase II study. Breast Cancer Res Treat 79: 391-397.

24. Peters JM, Foreman JE, Gonzalez FJ (2011) Dissecting the role of peroxisome proliferator-activate receptor- $\beta / \delta(\operatorname{PPAR} \beta / \delta)$ in colon, breast, and lung carcinogenesis. Cancer Metastasis Rev 30: 619-640.

25. Daikoku T, Tranguch S, Chakrabarty A, Wang D, Khabele D, et al. (2007) Extracellular signal-regulated kinase is a target of cyclooxygenase-1peroxisome proliferator-activated receptor-delta signaling in epithelial ovarian cancer. Cancer Res 67: 5285-5292.

26. Jarvis MC, Gray TJ, Palmer CN (2005) Both PPARgamma and PPARdelta influence sulindac sulfide-mediated p21WAF1/CIP1 upregulation in a human prostate epithelial cell line. Oncogene 24: 8211-8215.

27. Yin Y, Russell RG, Dettin LE, Bai R, Wei ZL, et al. (2005) Peroxisome proliferator-activated receptor delta and gamma agonists differentially alter tumor differentiation and progression during mammary carcinogenesis. Cancer Res 65: 3950-3957.

28. Garcia-Escudero R, Paramio JM (2008) Gene expression profiling as a tool for basic analysis and clinical application of human cancer. Mol Carcinog 47: 593-579.

29. van 't Veer LJ, Dai H, van de Vijver MJ, He YD, Hart AA, et al. (2002) Gene expression profiling predicts clinical outcome of breast cancer. Nature 415: 530-536.

30. Wei JS, Greer BT, Westermann F, Steinberg SM, Son CG, et al. (2004) Prediction of clinical outcome using gene expression profiling and artificial neural networks for patients with neuroblastoma. Cancer Res 64: 6883-6891.

31. McDonnell DP, Chang CY, Norris JD (2001) Capitalizing on the complexities of estrogen receptor pharmacology in the quest for the perfect SERM. Ann N Y Acad Sci 949: 16-35.

32. Hall JM, Couse JF, Korach KS (2001) The multifaceted mechanisms of estradiol and estrogen receptor signaling. J Biol Chem 276: 36869-36872.

33. Rosen ED, Spiegelman BM (2001) PPARgamma : a nuclear regulator of metabolism, differentiation, and cell growth. J Biol Chem 276: 37731-37734.

34. Frasor J, Danes JM, Komm B, Chang KC, Lyttle CR, Katzenellenbogen BS (2003) Profiling of estrogen up- and down-regulated gene expression in human breast cancer cells: insights into gene networks and pathways underlying estrogenic control of proliferation and cell phenotype. Endocrinology 144: 4562-4574.

35. Gupta RA, Brockman JA, Sarraf P, Willson TM, DuBois RN (2001) Target genes of peroxisome proliferator-activated receptor gamma in colorectal cancer cells. J Biol Chem 276: 29681-29687.

36. Shearer BG, Steger DJ, Way JM, Stanley TB, Lobe DC, et al. (2008) Identification and characterization of a selective peroxisome proliferatoractivated receptor beta/delta (NR1C2) antagonist. Mol Endocrinol 22: 523-529.

37. Mettu NB, Stanley TB, Dwyer MA, Jansen MS, Allen JE, et al. (2007) The nuclear receptor-coactivator interaction surface as a target for peptide antagonists of the peroxisome proliferator-activated receptors. Mol Endocrinol 21: 2361-2377.

38. Cronet P, Petersen JF, Folmer R, Blomberg N, Sjoblom K, et al. (2001) Structure of the PPARalpha and -gamma ligand binding domain in complex with AZ 242; ligand selectivity and agonist activation in the PPAR family. Structure 9: 699-706.

39. Forman BM, Chen J, Evans RM (1997) Hypolipidemic drugs, polyunsaturated fatty acids, and eicosanoids are ligands for peroxisome proliferator-activated receptors alpha and delta. Proc Natl Acad Sci USA 94: 4312-4317.

40. Kliewer SA, Sundseth SS, Jones SA, Brown PJ, Wisely GB, et al. (1997) Fatty acids and eicosanoids regulate gene expression through direct interactions with peroxisome proliferator-activated receptors alpha and gamma. Proc Natl Acad Sci USA 94: 4318-4323.

41. Liu KG, Lambert MH, Ayscue AH, Henke BR, Leesnitzer LM, et al. (2001) Synthesis and biological activity of L-tyrosine-based PPARgamma agonists with reduced molecular weight. Bioorg Med Chem Lett 11: 3111-3113.

42. Stanley TB, Leesnitzer LM, Montana VG, Galardi CM, Lambert MH, et al. (2003) Subtype specific effects of peroxisome proliferator-activated receptor ligands on corepressor affinity. Biochemistry 42: 9278-9287.

43. Panday K, Gona A, Humphrey MB (2014) Medication-induced osteoporosis: screening and treatment strategies. Ther Adv Musculoskelet Dis 6: 185-202.

44. Bird BR, Swain SM (2008) Cardiac toxicity in breast cancer survivors: review of potential cardiac problems. Clin Cancer Res 14: 14-24.

45. Conte P, Frassoldati A (2007) Aromatase inhibitors in the adjuvant treatment of postmenopausal women with early breast cancer: Putting safety issues into perspective. Breast J 13: 28-35.

46. Patel RR, Sharma CG, Jordan VC (2007) Optimizing the antihormonal treatment and prevention of breast cancer. Breast Cancer 14: 113-122.

47. Dannenberg AJ, Subbaramaiah K (2001) Treating cancers associated with overexpression of class I family of receptor tyrosine kinases. In: USP Office 6,291,496: 1-16.

48. Konopleva M, Zhang W, Shi YX, McQueen T, Tsao T, et al. (2006) Synthetic triterpenoid 2-cyano-3,12-dioxooleana-1,9-dien-28-oic acid induces growth arrest in HER2-overexpressing breast cancer cells. Mol Cancer Ther 5: 317-328.

49. Chen A, Xu J Activation of PPAR\{gamma\} by curcumin inhibits Moser cell growth and mediates suppression of gene expression of cyclin D1 and EGFR (2005) Am J Physiol Gastrointest Liver Physiol 288: G447-456.

50. Liu J, Wang H, Zuo Y, Farmer SR (2006) Functional interaction between peroxisome proliferator-activated receptor gamma and beta-catenin. Mol Cell Biol 26: 5827-5837.

51. Rovito D, Giordano C, Vizza D, Plastina P, Barone I, et al. (2013) Omega-3 PUFA ethanolamides DHEA and EPEA induce autophagy through PPAR $\gamma$ activation in MCF-7 breast cancer cells. J Cell Physiol 228: 1314-1322.

52. Teresi RE, Waite KA (2008) PPAR, PTEN, and the Fight against Cancer. PPAR Res 2008: doi: 10.1155/2008/932632.

53. Gupta RA, Tan J, Krause WF, Geraci MW, Willson TM, et al. (2000) Prostacyclin-mediated activation of peroxisome proliferator-activated receptor delta in colorectal cancer. Proc Natl Acad Sci U S A 97: 13275-13280. 
Citation: Hall JM, Robinson ML (2015) Peroxisome Proliferator-Activated Receptor $\mathrm{y}$ as a Therapeutic Target in Human Breast Cancer. J Steroids Horm Sci 6: 1000.155. doi:10.4172/2157-7536.1000.155

Page 9 of 9

54. Takayama O, Yamamoto H, Damdinsuren B, Sugita Y, Ngan CY, et al. (2006) Expression of PPARdelta in multistage carcinogenesis of the colorectum: implications of malignant cancer morphology. Br J Cancer 95: 889-895.

55. Barz T, Hoffmann A, Panhuysen M, Spengler D (2006) Peroxisome proliferator-activated receptor gamma is a Zac target gene mediating Zac antiproliferation. Cancer Res 66: 11975-11982.

56. Chavarro JE, Rich-Edwards JW, Rosner BA, Willett WC (2007) Dietary fatty acid intakes and the risk of ovulatory infertility. Am J Clin Nutr 85 231-237.
57. Friedrich MJ (2004) To "E" or not to "E," vitamin E's role in health and disease is the question. Jama 292: 671-673.

58. Han J, Hajjar DP, Zhou X, Gotto AM Jr, Nicholson AC (2002) Regulation of peroxisome proliferator-activated receptor-gamma-mediated gene expression. A new mechanism of action for high density lipoprotein. J Biol Chem 277: 23582-23586. 